\title{
PROSES DAN MAKNA SIMBOL RITUAL MUNJONG DAYAK TOBAG
}

\author{
Yusuf Olang \\ Yudita Susanti \\ Marselina Risca
}

SKIP Persada Khatulistiwa Sintang, Kalimantan Barat

e-mail: Yusufolang@gmail.com, yuditasusanti@gmail.com, Marselina.risca@yahoo.id,

\begin{abstract}
Abstrak: Masyarakat Tebang Benua memiliki tradisi mengucap syukur setelah dilakukannya pemanenan padi. Di setiap prosesi tradisi terdapat pemberian sesajen, sesajen tersebut memuat bagaimana proses ritual dan makna simbol yang menjadi kearifan lokal. Penelitian ini bertujuan mendeskripsikan proses dan makna simbol pada ritual Munjong Dayak Tobag.

Penelitian ini menggunakan metode kualitatif dan dijabarkan secara deskriptif. Sumber data dalam penelitian dari Pati Adat, Temenggung yaitu orang-orang penting yang mempunyai peran khusus dalam acara ritual Munjong tersebut. Teknik pengumpulan data yang digunakan adalah teknik observasi non partisipan, wawancara tidak terstruktur, dokumentasi. Alat pengumpulan data yang digunakan yaitu lembar observasi, pedoman wawancara, dokumentasi. Teknik validitas data dalam penelitian ini menggunakan teknik triagulasi sumber dan analisis datanya menggunakan analisis interaktif yang terdiri dari pengumpulan data, reduksi data, penyajian data, dan penarikan kesimpulan.

Hasil penelitian menunjukan bahwa ritual Munjong ini merupakan ritual sebagai ungkapan syukur atas hasil panen padi yang selama ini mereka tanam. Simbol dalam ritual sesajen yang sudah disiapkan yaitu sebagai persembahan rasa syukur kepada Tuhan Yang Maha Esa atas limpahan hasil padi mereka. Makna tradisi dalam ritual ini adalah ungkapan rasa syukur masyarakat Dayak Tobag atas hasil panen padi mereka yang baik. Dalam pelaksanaan ritual ini yang berpartisipasi adalah Kepala Adat, Pati Adat dan Temenggung.
\end{abstract}

Kata Kunci: Proses Ritual dan Makna Simbol 
PROCESS AND SYMBOLS MEANING OF RITUAL MUNJONG DAYAK TOBAG

\author{
Yusuf olang \\ Yudita Susanti \\ Marselina Risca
}

SKIP Persada Khatulistiwa Sintang, West Kalimantan

e-mail: Yusufolang@gmail.com, yuditasusanti@gmail.com, Marselina.risca@yahoo.id,

\begin{abstract}
The Tebang Benua community has a tradition of giving thanks after harvesting rice. In every procession of tradition there ae offerings, the offerings include the ritual process and the meaning of symbols that become local wisdom. This study aims to describes the process and meaning of symbols in the Munjong Dayak Tobag ritual. This study uses qualitative methods and is described descriptively. The source of data in research from Pati Indigenous, Temenggong are important people who have a special role in the Munjong ritual. Data collection techniques used were non-participant observation techiques, unstructured interviews, documentation. Data collection tools used were obsevation sheets, quidelines, interview, documentation. Data validity techniques in this study used soure triagulation techniques and data analysis using interactive analysis consisting of data collection, data reducation, data presentation, and drawing conclusions.

The results showed that this Munjong ritual was a ritual as an expression of gratitude for the rice harvest that they had been planting. The Symbol in the ritual offering that have been prepared is a gift of gratitude of the Almighty God for the abundance of their rice products. The meaning of tradition in this ritual is an expression of gratitude for the Dayak Tobag people for their good rice hervest. In carrying out this ritual the participants will be the Customary Chief, Customary Pati and Temenggong.
\end{abstract}

Keywords: Ritual Process, Symbol Meaning 


\section{A. PENDAHULUAN}

Sastra Lisan dan kesusastraan yang mencakup ekspresi kesusastraan masyarakat suatu daerah maka kami mencoba untuk meneliti kebudayaan yang disebarkan dan diturunkan secara lisan (dari mulut ke mulut). Jadi segala kebudayaan yang dituturkan secara lisan dan diwariskan dengan metode lisan termasuk dalam kajian sastra lisan, yang meliputi cerita rakyat, teka-teki rakyat, drama kerakyatan, syair, gurindam, dan lain sebagainya. Proses ritual adalah urutan pelaksanaan atau kejadian (peristiwa) yang terjadi secara alami tanpa rekayasa. Dalam sebuah proses memungkinkan menggunakan waktu, ruang, keahlian atau sumber daya yang bisa menghasilkan suatu hasil kepercayaan masyarakat Dayak tobag.

Ritual Munjong merupakan salah satu diantara bentuk aktualisasi budaya dayak di Kalimantan Barat. Budaya dan nilai-nilai spiritual yang di yakini memiliki misi membangun kebersamaan ditengah masyarakat dan sebagi perwujudan rasa terima kasih atas perlindungan dan berkat dari Tuhan (Jubata). Makna Simbol dapat dijumpai dimana-mana termasuk dalm sebuah ritual dan memiliki arti dan makna sendiri. Suatu tanda atau lambang yang terlihat dan mengandung arti/makna disebut Simbol, seperti halnya pada proses ritual Munjong Dayak Tobag, terbukti dengan adanya alat-alat yang digunakan dalam proses ritual yang menjadi kepercayaan diri suatu masyarakat tepatnya masyarakat Desa Tebang Benua dalam Ritual Munjong. Rumusan masalah dalam penelitian ini adalah bagaimanakah proses ritual Munjong Dayak Tobag dan bagaimanakah makna simbol ritual Munjong Dayak Tobag.

Endraswara (2013:151), sastra lisan adalah karya yang penyebarannya disampaikan dari mulut ke mulut secara turun-temurun. Sastra lisan berisi cerita-cerita yang disampaikan secara lisan dan bervariasi. Menurut Saputra dalam Desi (2016:15) Proses ritual adalah ritual yang dilakukan oleh masyarakat dengan menggunakan perlengkapan sesajen untuk mewujudkan keharmonisan atau keselarasan. Menurut Rene Wellek dan Austin Warren (2014:219) "Makna Simbol” juga melahirkan aliran sastra, yaitu simbolisme, seperti "citra", simbol muncul dalam konteks yang sangat beragam dan digunakan untuk berbagai tujuan. Makna Simbol adalah suatu istilah dalam logika, matematika, semantik, semiotik, dan epistemologi; simbol juga memiliki sejarah panjang di dunia teotologi ("simbol" adalah sebuah sinonim dari "kepercayaan"), di bidang seni, rupa, dan puisi.

\section{B. METODE PENELITIAN}

Metode penelitian yang digunakan dalam penelitian ini yaitu metode penelitian kualitatif. Metode kualitatif adalah prosedur yang menghasilkan data-data deskriptif berupa kata-kata tertulis atau lisan dari orang-orang dan perilaku yang diamati”. Moleong (2017:4) berpendapat bahwa "Data yang dikumpulkan adalah berupa kata-kata gambar, dan bukan angka-angka. Hal ini disebabkan dengan adanya penerapan metode kualitatif. Selain itu, semua yang dikumpulkan berkemungkinan menjadi kunci terhadap apa yang sudah diteliti”. Data Penelitian ini adalah berupa foto-foto, video, dan hasil wawancara. Sumber data peneltian adalah masyarakat Desa Tebang Benua 
Dayak Tobag. Mukhtar dalam Desi (2016:21) subjek adalah orang yang berada dalam masyarakat yang ditetapkan sebagai pemberi informasi dalam penelitian atau yang disebut informen.

Menurut Sugiyono (2013:145) dalam observasi ini peneliti tidak terlibat dengan dalam kegiatan hanya mengamati orang yang diamati atau yang digunakan sebagai sumber data penelitian. Dengan Observasi merupakan pengamatan langsung terhadap fenomena yang dikaji. Pengamatan ini diharapkan dapat melengkapi data dari wawancara. Metode observasi yang digunakan dalam penelitian ini adalah non partisipasi karena peneliti hanya mengamati dari ritual Munjong, sehingga tidak menuntut banyak keterlibatan peneliti terhadap fenomena dari apa yang diteliti berkaitan dengan focus pengamatan di atas yang peneliti akan amati yaitu berkaiatan dengan ritual Munjong. Menurut Sugiyono (2013:140) wawancara tidak terstruktur adalah wawancara yang bebas dimana peneliti tidak menggunakan pedoman wawancara yang telah tersusun secara sistematis dan lengkap untuk pengumpulan datanya. Pedoman wawancara hanya menggunakan garis-garis besar permasalahan yang akan ditanyakan. Menurut Sugiyono (2015:329) "Teknik dokumentasi merupakan catatan peristiwa yang sudah berlalu, dokumentasi dapat berbentuk gambar, tulisan dan berupa foto-foto". Teknik ini digunakan penelitian untk memperkuat data penelitian dengan mencantumkan beberapa foto mengenai proses ritual.

\section{PEMBAHASAN}

1. Proses Ritual Munjong Dayak Tobag Seperti kebanyakan ritual adat, ritual Munjong juga butuh proses dalam pelaksanaannya.

Proses atau punalur pelaksanaan dari ritual Munjong itu sendiri adalah sebagai berikut :

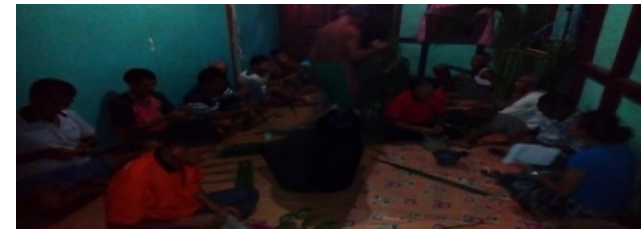

Gambar 1.1 Tim Peribuh (Panitia Ritual)

1.1 Betumu Bopokat adalah proses awal dari rencana kegiatan ritual Munjongi ni. Kegiatan ini adalah wadah bertemunya para tetua-tetua adat, kepala desa, tumenggung, serta pengurus adat setempat dimana para tokoh masyarakat dan organisasi pemuda adat setempat berkumpul bersama dan saling bertukar pendapat tentang rencana kegiatan yang akan dilaksanakan.

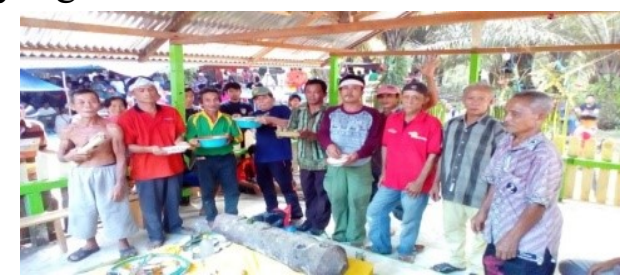

Gambar 1.2 Pengurus Adat dan aparat desa 


\subsection{Muat Peribuh}

Muat Peribuh adalah para perangkat/pengurus adat dan pengurus desa serta masyarakat sekitar berkumpul dalam menyiapkan segala peralatan dan keperluan dalam melaksanakan ritual Munjong.

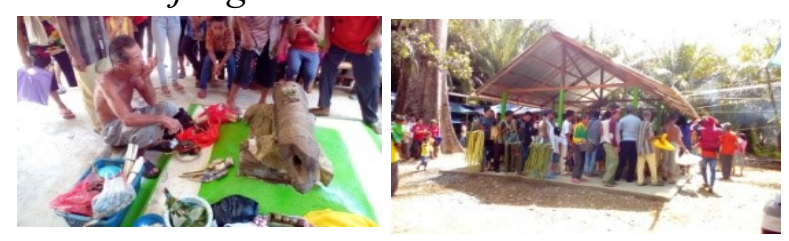

Gambar 1.3 Proses Ritual

\subsection{Muka Basa}

Muka Basa adalah rangkaian pembacaan doa dan mantra-mantra kepada sang pencipta guna meminta izin untuk dilaksanakannya ritual Munjong tersebut.
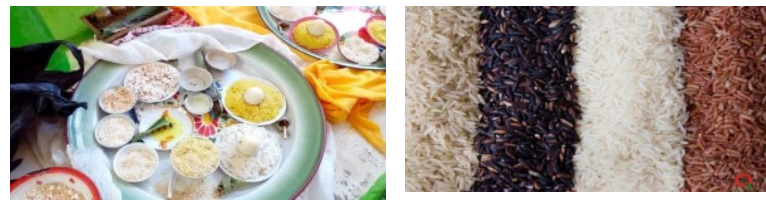

Gambar 1.4 Padi yang sudah diolah menjadi beras

1.4 Ngolap Semongat Padi

Ngolap Semongat Padi merupakan salah satu ritual dimana para pengurus adat dan Tumenggung berkumpul di suatu lahan pertanian masyrakat dalam rangka memanggil semangat (arwah) padi.

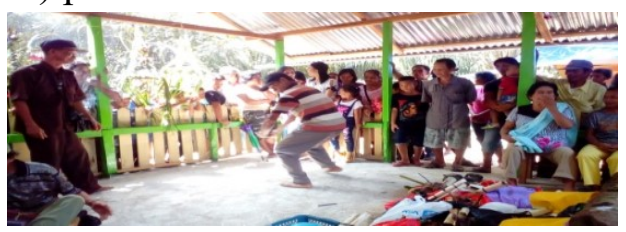

Gambar 1.5 Pendo’a/pemantra melakukan Ritual

\subsection{Betenteng}

Betenteng merupakan sejenis arak-arakan dari pelakon ritual mengelilingi kampong membawa sesajen ancak yang sudah dibuat dan disusun sedemikian rupa.

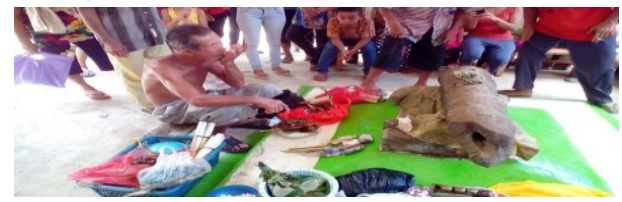

Gambar 1.6 Mandikan Meriam di Pusat Ritual

1.6 Nyuci Mane Meriam Pedagi

Nyuci Mane Meriam Pedagi dilakukan di pedagi yaitu tempat di pusat ritual Munjong dilakukan.

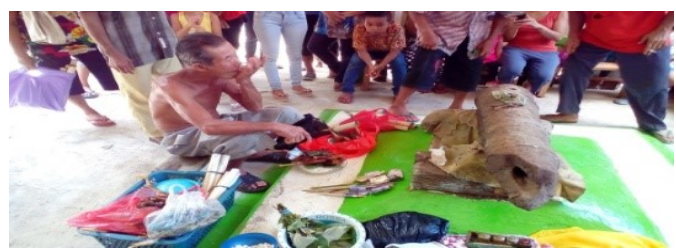

Gambar 1.7 Pemantra meminta Berkat/Rejeki kepada Tuhan (Jubata) 


\subsection{Bepamang Minta Berokat}

Bepamang Minta Berokat adalah di dalam kegiatan ini masyarakat berkumpul dan menyerahkan sesajen kepada para pengurus adat dan Tumenggung guna minta didoakan agar mereka bias memperoleh kesehatan dan diberikan rejeki yang cukup dalam kehidupan mereka.

\section{Makna-makna Simbol dalam Ritual Munjong Dayak Tobag}

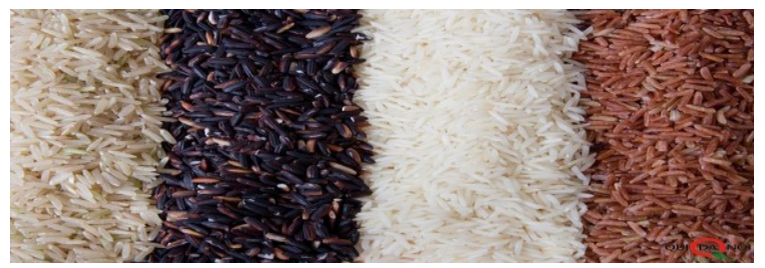

Gambar 2.1 Ketan Merah, Putih, Hitam

2.1 Ketan putih melambangkan hati yang bersih dan suci dalam melakukan ritual tersebut sehingga mempermudah seseorang dalam menyampaikan permohonannya.

2.2 Ketan merah melambangkan keberanian dan kemenangan.

2.3 Ketan hitam melambangkan kemampuan dari seseorang untuk melawan pengaruh negatif dari dalam maupun dari luar diri seseorang.

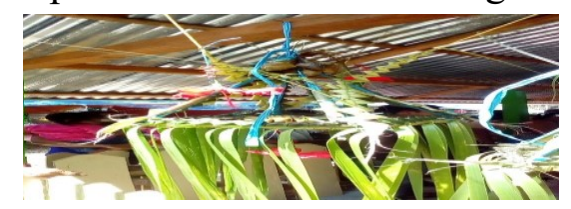

Gambar 2.4 Daun Kelapa

2.4 Daun kelapa melambangkan kehidupan yang makmur dan sejahtera seperti pohon kepala yang dapat dimanfaat untuk kehidupan manusia.

2.5 Daun kelapa berbentuk kris melambangkan keluarga yang selalu berbahagia dan keluar dari masalah-masalah yang ada dikehidupan.

2.6 Ketupat melambangkan anyaman kulit yang rumit dan saling tumpang tindih mencerminkan perjalanan hidup yang sering kali diselingi oleh kesulitan dan masalah.

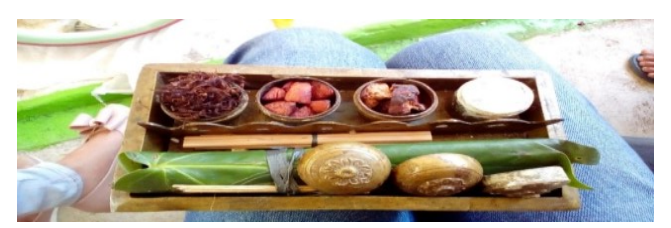

Gambar 2.7 Tembakau, Pinang Gambir, Kapur Rokok, Sirih

2.7 Tembakau melambangkan hati yang tabah dan rela berkorban demi orang lain.

2.8 Pinang melambangkan keturunan yang baik karna dilihat dari pohonya yang menjulang ke atas serta ada harapan mendapatkan keturunan yang baik dan sukses.

2.9 Gambir melambangkan keteguhan hati.

2.10 Kapur melambangkan hati yang putih bersih dan serta tulus.

2.11 Sirih menyimbolkansifatrendahhatidanmemuliakan orang lain. 


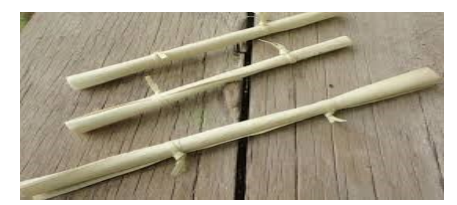

Gambar 2.12 Roko Daun Nipah

2.12 Rokok menjadi penanda dan pembuka bahasa bahwa prosesi ritual yang dilaksanakan telah resmi dan sah secara adat serta diharapkan dengan suguhan rokok tersebut dapat memperoleh izin dan seluruh rangkaian kegiatan ritual berjalan lancar.

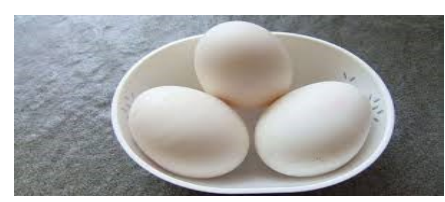

Gambar 2. 13 Telur

2.13 Telur mempunyai arti bahwaharapankedepannyamasyarakatakan mendapatkan rejeki yang melimpah.

2.14 Benang tetebus jarum adalah jika kita mengerjakan sesuatu seharusnya dilakukan sampai tuntas artinya apapun yang kita mulai seharusnya diselesaikan secara sempurna.

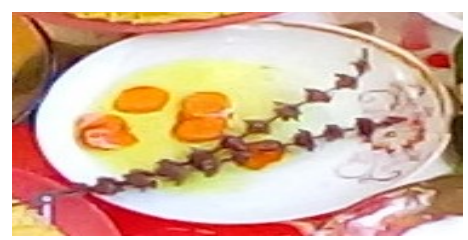

Gambar 2.15 Gambar Minyak dan 7 irisan kunyit

2.15 Minyak goreng, bunga selasih dan 7 kunyit. Minyak goreng sendiri melambang kelembutan atau pelancar jadi dalam setiap ikhtiar yang akan dilakukan. Sedangkan 7 iris kunyit(memiliki warna kuning yang melambangkan kejayaan) merupakan hitungan keramat atau sakral suku dayak dalam sebuah ritual sedangkan daun selasih hanya sebagai alat pengoles saja.

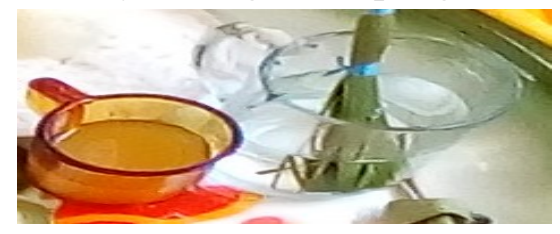

Gambar 2.16 Air Putih dan Tuak

2.16 Air putih dan tuak digunakan untuk menyirami meriam tua yang diakui warga bahwa meriam keramat tersebut sebagai penjaga keselamatan kampung serta menjauhkan hasil berpadi mereka terjauhkan dari kegagalan dalam menanam padi. Tuak tersebut mempunyai makna keakraban.

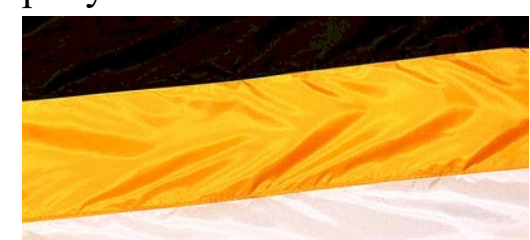

Gambar 2.17 Kain Kuning 
2.17 Kain kuning dan Kain Putih. Kain kuning ini melambangkan simbol kejayaan atau puncak keemasan dimana diharapkan ke depanya seluruh masyarakat mengalami puncak kejayaan disegala bidang usahanya.Kain putih ini melambangkan kebersihan dan kesucian.

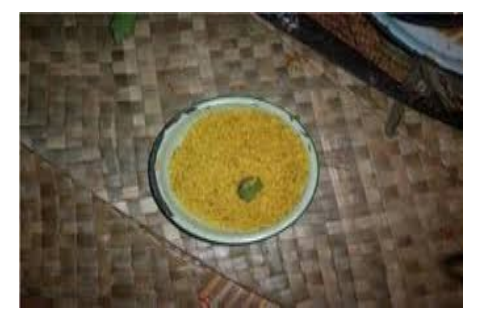

Gambar 2.18 Beras Kuning

2.18 Beras kuning mempunyai makna sebagai alat untuk memanggil roh-roh halus dalam proses ritual tersebut dengan maksud meminta bantuan supaya pelaksanaan ritual tersebut berjalan lancar.

\section{Proses Ritual Munjong pada Masyarakat Dayak Tobag}

Proses awal ritual yang dilakukan dalam ritual Munjong Dayak Tobag sekumpulan Kepala Adat, Pati adat, Temenggung menyiapkan segala persiapan dan bahan-bahan yang diperlukan dalam proses ritual Munjong berupa topok (tempat menyimpan sirih, kapur, gambir, tembakau), sirat (berisi pinang muda, kapur, tembakau, gambir), Birak (7 buah lidi yang diikat), tujuh pales (2 ruas bambu berisi pulut dan tumpi), sungkui (daun yang di isi pulut), dan ketupat ( daun kelapa berisi pulut).

Proses Ritual Munjong pada masyarakat dayak Tobag yang pertama dilakukan mempersiapkan sesajen yang akan dipersembahkan ke tempat yang akan dilakukannya ritual Munjong. Setelah semua sesajen telah lengkap maka akan ada tanda 3 kali tembakan bahwa ritual akan dimulai dimana para Kepala Adat, Pati Adat, Temenggung akan menuju tempat ritual Munjong yang disebut Pedagi dengan membawa sesajen yang sudah dipersiapkan yang juga diringi dengan alunan alat musik. Setelah sampai ke tempat ritual para Kepala Adat, Pati Adat, Temenggung sesajen diletakan pada tempat ritual, kemudian Para Kepala Adat, Pati Adat, dan Temenggungmengelilingi tempat ritual yang disebut Pedagi sebanyak 7 kali. Setelah selesai menggelilingi Pedagi akan ada tanda tembakan ke 4 ( 1 kali tembakan ) dimana Kepala Adat, Pati Adat, dan Temenggungakan membacakan serapah juga memberikan sesajen ke sebuah potongan meriam tua (wasiat dari raja Tayan untuk dijaga yang juga dipercayai masyarakat Dayak Tobag sebagai penjaga Desa Tebang Benua atas segala yang buruk, potongan meriam tersebut bisa berbunyi jika ada terjadi hal buruk pada Desa Tebang Benua). Selanjutnya Kepala Adat, Pati Adat, dan Temenggungmemandikan potongan meriam dengan tuak, air, minyak, dan air tepung sebanyak 7 kali juga memberi makan ke meriam tersebut dengan sesajen yang sudah dipersiapkan. Setelah semua dilakukan Kepala Adat akan memutari potongan meriam sebanyak 3 kali dengan membawa ayam jago yang masih hidup.Proses terakhir dalam ritual Munjong akan ada tanda tembakan ke 5 (1 kali tembakan) dimana akan dilakukannya seserahan yaitu pembacaan niat/pembacaan doa 
syukur atas hasil panen padi selama 6 bulan, kesehatan yang diberikan. Selanjutnya semua sesajen yang sudah dipersiapkan dilemparkan ke arah matahari sebanyak 3 kali juga dilemparkan 2 kali dilemparkan ke potongan meriam.

\section{Makna Simbol}

Simbol atau tanda dapat dilihat sebagai konsep yang dianggap oleh manusia sebagai pengkhasan sesuatu yang lain. Simbol adalah objek, kejadian, bunyi bicara, atau bentuk-bentuk tulis atau benda yang diberi makna oleh manusia. Bentuk primer dari simbolisasi oleh manusia adalah melalui bahasa. Tetapi manusia juga berkomunikasi memungkinkan tanda dan simbol dalam bentuk lain seperti lukisan, tarian, musik, arsitektur, pakaian, perhiasan dan lain sebagainya. Begitu juga yang terdapat dalam tradisi ritual Munjong.

Menurut teori sastra, simbol sebaiknya dipakai dalam pengertian sebagai berikut: sebagai objek yang mengacu pada objek lain, tetapi juga menuntut perhatian pada dirinya sendiri sebagai suatu perwujudan. Simbol keagamaan didasarkan pada suatu hubungan intrinsik antara "tanda" dan objek yang diacu oleh tanda itu, baik dalam bentuk metanimia maupun metafora contohnya seperti salib, sebuah bulan sabit, atau seekor ulat berbulu yang dikaitkan dengan mitos-mitos.

Bahasa simbol mempunyai peranan penting dalam kehidupan sehari-hari dan dalam beragama. Penggunaan simbol dalam kehidupan masyarakat nampak dengan adanya ritual adat yang merupakan warisan turun menurun dari generasi tua kegenerasi muda. Pandangan masyarakat tentang ritual-ritual yang terjadi disekitar masyarakat, mengandung adat-istiadat yang sangat kental.

Ada pandangan yang menganggap sombilisme "hanya simbolisme". Menurut pandangan ini, puisi dan agama hanyalah citraan indrawi yang disusun secara ritual atau sebaliknya, "tanda" dan "makna" dianggap kosong, karena tidak dapat menjangkau kenyataan moral atau filsafat yang teranseden. Ada pandangan lain yang menganggap simbolisme sebagai usaha yang dilakukan dengan sengaja, terencana, dan sangat diperhitungkan, untuk menerjemahkan (secara mental) konsep-konsep menjadi istilahistilah yang ilustratif, indrawi, dan didaktis.

Menurut Endraswara (2012:171) kata simbol berasal dari kata Yunani yaitu symbolon yang berarti tanda atau ciri yang memberitahukan sesuatu kepada seseorang. Manusia dalam hidupnya selalu berkaitan dengan simbol-simbol yang berhubungan dengan kehidupan sehari-hari. Manusia adalah animal symbolicum, artinya bahwa pemikiran dan tingkah laku simbolis merupakan ciri yang betul-betul khas manusiawi dan bahwa seluruh kemajuan kebudayaan manusia berdasarkan diri pada kondisikondisi itu.Manusia adalah makhluk budaya dan budaya manusia penuh dengan simbol, sehingga dapat dikatakan bahwa budaya manusia penuh diwarnai dengan simbolisme yaitu suatu tata pemikiran atau paham yang menekankan dan mengikuti pola-pola yang mendasarkan diri kepada simbol atau lambang.

Dalam mengkaji dan menganalisis proses dan makna simbol ritual-ritual Munjong, teori yang digunakan peneliti adalah teori simbolik atau teori simbol. Di mana 
yang kita ketahui bahwa manusia adalah makhluk budaya dan budaya manusia itu penuh dengan simbol, bahkan bisa dikatakan bahwa budaya manusia penuh diwarnai dengan simbolisme yaitu suatu tata pemikiran atau paham yang menekankan atau mengikuti pola-pola yang mendasarkan diri kepada simbol atau lambang. Begitu juga dengan proses ritual penggarapan padi tidak terlepas dari simbol-simbol religi.

Dengan adanya ritual warga suatu masyarakat bukan hanya diingatkan tetapi dibiasakan untuk menggunakan simbol-simbol yang bersifat abstrak yang berada pada tingkat pemikiran untuk berbagai kegiatan sosial yang nyata yang ada dalam kehidupan mereka sehari-hari.

Simbol adalah objek atau peristiwa apapun yang menunjukan pada sesuatu. Dari pendapat tersebut maka dapat disimpulkan bahwa simbol adalah tanda, lambang, kata dan sebagainya yang mempunyai maksud tertentu misalnya untuk mengekspresikan sastra, seni atau sesajen.

\section{KESIMPULAN}

Ritual "Munjong" telah ada sejak zaman nenek moyang orang Dayak Tobag, Masyarakat Desa Tebang Benua yang mayoritas bekerja sebagai petani telah lama menjalankan tradisi ini, salah satu sesajen yang dianggap penting bagi masyarakat Tebang Benua adalah sesajen dalam membuka lahan pertanian sampai masa panen tiba. Masyarakat desa ini mempercayai adanya Jebata yang menjaga tanaman agar tidak terkena hama padi dan hasil panen berlimpah.

Makna-makna yang terdapat dalam tradisi "Munjong" adalah merupakan salah satu usaha manusia sebagai jembatan antara dunia manusia dengan dunia ritus (Tuhannya), melalui tradisi Selamatan Munjong ini diharapakan bisa menghubungkan manusia dengan leluhur, dan Tuhannya dan akan diberikan keselamatan dalam penggarapan lahan pertanian serta segala usaha dan pekerjaan mereka.

\section{DAFTAR PUSTAKA}

Endraswara, et al. 2013. Metode Penelitian Kebudayaan. Yogyakarta: Gajah Mada University Press.

Frestisari, Imma. "Makna Simbol Tari Nimang Padi dalam Upacara Adat Naek dango masyarakat Dayak kanayant. Volume 02 No.01 Hal 2016.

Murti. 2015. "Prosesi Makna Simbolik Upacara Tradisi Wiwit Padi di Desa Silendung Kecamatan Gebang Kabupaten Puwerjo". Volume 06 No.05 Hal 68.

Moleong, L. J. 2017. Metodologi penelitian Kulalitatif. Bandung:PT. Remaja Rosda Karya Offset.

Sugiyono. 2015. Metode Penelitian Kuantitatif, kualitatif dan R\&D. Bandung: Alfabet. Wellek Rene \& Warren Austin. 2014. Teori Kesusastraan. Jakarta: PT Gramedia. 